\title{
TERRITÓRIOS EXISTENCIAIS E NARRATIVAS DE TRAJETÓRIAS ESCOLARES
}

\section{DINA MARIA ROSÁRIO DOS SANTOS}

RESUMO

\section{ABSTRACT}

Este artigo apresenta o processo de construção e os territórios existenciais, tomados como intercessores deleuzo-guattarianos, produzidos no âmbito da pesquisa "Nômades do Saber: uma cartografia de trajetórias escolares migrantes na Bahia/Brasil". Tais territórios emergem das entrevistas narrativas utilizadas na pesquisa, como recurso para acessar os deslocamentos físicos e simbólicos que compõem as trajetórias escolares migrantes e as linhas de fuga ao mapa geopolítico do conhecimento. As narrativas agudam a sua importância no momento em que são acolhidas na sua singularidade heurística. Os territórios são espaços sociopolíticos e histórico-culturais produzidos/produtores de subjetividades. Os territórios são o palco dos dinâmicos mapas psicossociais trazidos à tona pelas narrativas. Escolher trabalhar com narrativas biográficas requer desvelo pelo inusitado. 0 artigo arrisca ponderar sobre o uso dos territórios existenciais como estratégia para análise/interpretação de narrativas.

Palavras-chave: Entrevista narrativa. Território existencial. Trajetória escolar. Cartografia.

\section{EXISTENTIAL TERRITORIES AND NARRATIVE OF SCHOOL TRAJECTORIES}

This article presents the construction process and the existential territories, taken as a Deleuze\&Guattari's intercessors, produced within the research "Nomads of wisdom: the cartography of school migrant trajectories in Bahia/Brazil". Such territories emerge from the narrative interviews used in the research as a resource to access the physical and symbolic displacements that compose the school migrant trajectories and the lines of flight to the geopolitical map of knowledges. The narratives improve its importance as they are welcomed in their heuristic singularity. The territories are at the same time social, political, historical and cultural space; produced and producers of subjectivities. The territories are the stage of psychosocial dynamic maps brought to light by the narratives. To work with biographical narratives requires devotion to the unusual. The article takes the 
risks to consider the use of existential territories as a strategy for analysis/interpretation of narratives.

Keywords: Narrative interview. Existential territory. School trajectory. Cartography.

\section{RESUMEN TERRITORIOS EXISTENCIALES Y NARRATIVAS DE TRAYECTORIAS ESCOLARES}

Este artículo presenta el proceso de construcción y los territorios existenciales, tomados como intercesores deleuzo-guattarianos, producidos en el ámbito de la investigación "Nómadas del saber: una cartografia de las trayectorias escolares migrantes en Bahia/Brasil". Tales territorios emergen de las entrevistas narrativas utilizadas en la investigación como un recurso para acceder a los desplazamientos físicos y simbólicos que componen las trayectorias escolares migrantes y las líneas de fuga del mapa geopolítico del conocimiento. Las narrativas agudizan su importancia en la medida en que son acogidas en su singularidad heurística. Los territorios son espacios socio-político-histórico-culturales producidos/productores de subjetividades. Los territorios son el escenario de los dinámicos mapas psicosociales puestos de manifiesto por medio de las narrativas. Elegir trabajar con narrativas biográficas requiere interés por lo inusitado. El artículo se aventura en ponderar sobre el uso de los territorios existenciales como una estrategia para el análisis/interpretación de las narrativas.

Palabras clave: Entrevista narrativa. Territorios existenciales. Trayectorias escolares. Cartografia.

\section{Introdução}

Este artigo apresenta o processo de construção e os territórios existenciais, tomados como intercessores deleuzo-guattarianos, produzidos no âmbito da pesquisa "Nômades do Saber: uma cartografia de trajetórias escolares migrantes na Bahia/Brasil". Tais territórios emergem das entrevistas narrativas utilizadas na pesquisa, como recurso para acessar os deslocamentos fisicos e simbólicos que compõem as trajetórias escolares migrantes e as linhas de fuga ao mapa geopolítico do conhecimento.

São as linhas de fuga ${ }^{1}$ e não o enraizamen-

1 Em "O vocabulário de Deleuze", Zourabichvili (2004) escreve: "Esses vetores de desorganização ou de 'desterritorialização' são precisamente designados como to que produzem a singularidade ${ }^{2}$ de uma in-

linhas de fuga. Compreendemos agora a dupla igualdade que constitui essa expressão complexa. Fugir é entendido nos dois sentidos da palavra: perder sua estanquidade ou sua clausura; esquivar, escapar. Se fugir é fazer fugir, é porque a fuga não consiste em sair da situação para ir embora, mudar de vida, evadir-se pelo sonho ou ainda transformar a situação (este último caso é mais complexo, pois fazer a situação fugir implica obrigatoriamente uma redistribuição dos possiveis que desemboca - salvo repressão obtusa - numa transformação ao menos parcial, perfeitamente improgramável, ligada à imprevisivel criação de novos espaços-tempos, de agenciamentos institucionais inéditos". (ZOURABICHVILI, 2004, p. 30)

2 Em "Micropolítica - cartografias do desejo", Guattari e Rolnik (2005) explicam: "Identidade e singularidade são duas coisas completamente diferentes. A singularidade é um conceito existencial; já a identidade é um conceito de referenciação, de circunscrição da realidade a quadros de referência, quadros esses 
vestigação. Como um rizoma, ${ }^{3}$ a construção de um estudo ocorre "[...] por variação, expansão, conquista, captura, picada" (DELEUZE; GUATTARI, 1995, p. 32). Uma pesquisa, assim como o rizoma, possui segmentaridades e linhas de fuga. Ao mesmo tempo em que se busca a territorialização e a reterritorialização ${ }^{4}$ em áreas do saber e teorias científicas, em teóricos e pesquisas nacionais e internacionais, é necessário permitir a desterritorialização como espaço para o novo, para o imprevisto, para as idiossincrasias do conhecimento em construção.

Este artigo arrisca-se a ponderar sobre o uso dos territórios existenciais como estratégia para a análise/interpretação de narrativas. Para tanto, o texto está organizado em três seções: a primeira trata das escolhas teóricometodológicas que geraram a tomada de decisão pelo uso dos territórios existenciais para pensar as trajetórias narradas no estudo; a segunda apresenta os territórios propriamente ditos; e a terceira lucubra sobre tais decisões.

\section{Aproximando-se...}

As trajetórias escolares são objeto de estudos sociológicos desde os anos 60 do século XX. Eram, naquele momento, entendidas a partir das relações entre os percursos dos indivíduos no sistema oficial de ensino e a origem social. Os estudos baseavam-se em análises longitu-

que podem ser imaginários. Essa referenciação vai desembocar tanto no que os freudianos chamam de identificação, quanto nos procedimentos policiais, no sentido da identificação do indivíduo - sua carteira, de identidade, sua impressão digital, etc. Em outras palavras, a identidade é aquilo que faz passar a singularidade de diferentes maneiras de existir por um só e mesmo quadro de referência identificável". (GUATTARI; ROLNIK, 2005, p. 68)

3 Daniel Lins esclarece a noção, deleuzo-guattariana, de rizoma, da seguinte forma: "O Rizoma é a horizontalidade que multiplica as relações e os intercâmbios que dele se originam. A vida assim compreendida é um contínuo fluxo e refluxo, potência de interação e produção de sentidos". (LINS, 2005, p. 1232)

4 Deleuze e Guattari explicam que a "desterritorialização: D é o movimento pelo qual 'se' abandona o território. É a operação da linha de fuga”. (DELEUZE; GUATTARI, 1995, p. 224). dinais do fluxo escolar e eram destituídas de aproximações às biografias dos sujeitos.

As diferenças entre percursos escolares de indivíduos de um mesmo grupo social passam, então, a ser cada vez mais estudadas. Deixa de ser suficiente apontar a relação entre origem social e destino escolar. Busca-se então compreender como essa relação é construída ao longo das trajetórias escolares. (NOGUEIRA; FORTES, 2004, p. 58)

Por volta dos anos de 1980, o enfoque vigente passa a abordar a diversidade de percursos, práticas e "destinos", no âmbito de um mesmo nível social, em função da utilização das histórias de vida e da assunção da subjetividade dos sujeitos aos processos acadêmicos vividos.

Atualmente, pode-se considerar a existência de uma "sociologia das trajetórias escolares" voltada para o estudo de trajetórias ditas atípicas - as que desviam-se da (pre)visão. Esses estudos, ainda que marcados pela complexidade e multiplicidade de aportes teóricos e metodológicos, coadunam-se à compreensão de que a trajetória escolar se diferencia em função da origem social e que fatores diversos colaboram, de forma interdependente, na construção do processo. Destacam-se hoje, no Brasil, os estudos de Maria Alice Nogueira, à frente do Observatório Sociológico Família-Escola da Universidade Federal de Minas Gerais.

Somam-se aos estudos de Nogueira (2000), Nogueira e Fortes (2004) as pesquisas de Bourdieu (1992; 1999), Mizukami (1996) e Zago (2006). Ainda que estejam marcadas pelo pluralismo teórico-metodológico, estas têm em comum a importância dada à análise das trajetórias escolares para a compreensão dos processos e estratégias de escolarização.

Na pesquisa que the dá origem e no artigo "Territórios existenciais e narrativas de trajetórias escolares - uma aproximação", compreende-se percurso escolar como a garantia 
do direito à educação pelo cidadão, através do acesso, permanência e fluxo escolar - trânsito pelas etapas e niveis do sistema escolar vigente. 0 percurso de cada aluno compõe-se da sucessão de séries/anos/ciclos através dos quais o sujeito avança nos níveis e modalidades do sistema oficial de ensino ofertado em nível público, particular ou através de ONG e outras associações.

0 percurso escolar atravessado pela história das pessoas converte-se em trajetória escolar. A compreensão da trajetória escolar como parte de um projeto de escolarização, no qual os deslocamentos intra e intermunicipais, estaduais, nacionais e internacionais, são estratégias para a sua concretização, nos permite falar em Trajetória Escolar Migrante.

Teórico-metodologicamente, o estudo que dá origem a este artigo propõe a construção de uma cartografia deleuzo-guattariana (1995). Trata-se de uma forma de cartografar, baseada nos princípios da esquizoanálise, ${ }^{5}$ que escreve cartas sobre paisagens psicossociais - afetos, movimentos e intensidades. Cartografar, aqui, refere-se às transitórias configurações territoriais da existência e se debruça por sobre indícios em busca das invisibilidades. "A cartografia parte do reconhecimento de que, o tempo todo, estamos em processos, em obra" (BARROS; KASTRUP, 2010, p.73).

O conceito de cartografia é apresentado por Gilles Deleuze e Félix Guattari na Introdução de Mil Platôs (1995). Nesta obra, a cartografia é apresentada com um dos seis princípios do rizoma. Um rizoma constitui-se a partir dos princípios de conexão, heterogeneidade, multiplicidade, ruptura, a-significação, cartografia e decalcomania.

5 [...]a Esquizoanálise não incide em elementos nem em conjuntos, nem em sujeitos, relacionamentos e estruturas. Ela só incide em lineamentos, que atravessam tanto os grupos quanto os indivíduos. Análise do desejo, a Esquizoanálise é imediatamente prática, imediatamente política, quer se trate de um indivíduo, de um grupo ou de uma sociedade. Pois, antes do ser, há a política. (DELEUZE; GUATTARI, 1996, p. 77-78)
Os territórios existenciais trazidos à tona pela cartografia são espaços compostos por linhas de força às quais se tem acesso por meio dos sentidos produzidos nas narrativas. Os territórios são locus de sentidos do desejo de vida, das invenções de vida vivida, das fugas em clamor de existências. Justamente por que "não há experiência humana que não possa ser expressa na forma de uma narrativa" (JOVCHELOVITCH; BAUER, 2002, p. 91) é que as narrativas são o brado e eco de imanências.

Narrativas são construções sígnicas e os processos para a sua análise voltam-se para a busca das significações "pertinentes ao objeto da pesquisa e que adquirem aí o status de indícios" (BERTAUX, 2010, p. 89). As narrativas dos Nômades do Saber agudam a sua importância no momento em que são acolhidas na sua singularidade heurística. Escolher trabaIhar com narrativas requer desvelo pelo inusitado. A narrativa, como atos de fala, está além do relato de eventos. As narrativas são ressignificadas no curso da narração. Porque atos de fala, a narrativa constitui os homens e as mulheres narradores à medida que produzem e organizam as experiências e os sentidos que se vão formado por meio da ação/reflexão de (re)contar a si e ao outro, por si e por outros.

\section{Mais próximo...}

Narrativas pessoais, biografias, etnobiografias, histórias de vida, autobiografias, etnografias, entrevistas narrativas, memórias populares... Eis parte do vasto leque das produções que abrangem as investigações narrativas. A hodiernidade - marcada pela efêmera velocidade da (des)construção, (re)configuração, (trans)formação dos processos, fenômenos e conhecimentos - requer abordagens que permitam o estudo do que está em curso (fatos, fenômenos, processos) e que tal seja anunciado/lucubrado pela voz de quem o produz. As narrativas vão ao encontro dessa necessidade 
contemporânea da escuta à voz "[...] de tudo que não se contabiliza e foge à fantasia da cifra. Do imaterial, de qualquer modo. Estando atentos 'ao preço das coisas sem preço' (J. Duvignaud) é que saberemos dar sentido a todos os fenômenos que não querem ter um sentido" (MAFESOLLI, 2001, p. 23). Justamente por isso abundam investigações narrativas em ciências sociais e em educação.

Ferrarotti (1988) aponta para necessidade de uma antropologia de caráter microssocial, voltada para a compreensão da vida cotidiana - dificuldades e contradições, tensões e problemas - e, na esteira dessa perspectiva, a renovação dos seus instrumentos heurísticos. Nesse contexto, Ferrarotti afirma que a biografia "se torna instrumento sociológico que parece poder vir a assegurar esta mediação do ato à estrutura, de uma história individual à história social" (FERRAROTTI, 1988, p. 20). Nóvoa (2000) afirma que a insatisfação com relação ao tipo de conhecimento produzido no âmbito das ciências e a emergência de um outro modo de produção de saberes promove o interesse dos pesquisadores das ciências sociais e humanas pelas biografias.

Pineau (2006) apresenta um quadro resumo do desenvolvimento dos estudos com histórias de vida (1980 a 2005). Com base em marcos evolutivos (emergência e desenvolvimento da corrente de pesquisa-formação; a publicação de obras; o lançamento de revistas; a criação de fundações, associações e redes internacionais e nacionais; a promoção de simpósios), Gaston Pineau propõe três períodos para o movimento: a) Eclosão - os anos 80 do século $X X$; b) Fundação - os 90 do mesmo século e; c) Desenvolvimento diferenciador os anos 2000.

De acordo com Riessman (1993), não há consenso, entre os teóricos, a respeito da definição de narrativa. Se por um lado, Labov (1982) considera que todas as narrativas são histórias posto que se reportam a acontecimentos passados; Riessman, tomando como exemplo as narrativas habituais, as narrativas hipotéticas e as narrativas temáticas, afirma que nem todas as narrativas são histórias. Elbaz-Luwisch (2002) propõe que, como expressão do vivido, nas narrativas, o espaço é curvo, o tempo é não linear e, ambos, interagem a seu favor.

De acordo com Clandinin e Connelly (2011), a pesquisa narrativa é método e fenômeno e pode ser definida como "o estudo da experiência como história, assim, é principalmente uma forma de pensar sobre a experiência" (CLANDININ; CONNELLY, 2011, p. 2). Delory-Momberger (2012), ao abordar a pesquisa biográfica, ressalta as inter-relações entre os homens e mulheres narradores, suas singularidades e suas vidas vividas. A autora destaca, ainda, o papel das subjetividades e dos processos de subjetivação na dialógica escuta da "exterioridade social e interioridade pessoal" (DELORY-MOMBERGER, 2012, p. 526) dos tempos e espaços das narrativas. Sobre o espaço da escuta dialógica, Delory-Momberger o descreve como:

[...] espaço heurístico que age sobre cada um dos envolvidos: o espaço do entrevistado na posição de entrevistador de si mesmo; o espaço do entrevistador, cujo objeto próprio é criar as condições e compreender o trabalho do entrevistado sobre si mesmo. (DELORY-MOMBERGER, 2012, p. 527)

A respeito da assunção da subjetividade e da validade/representatividade das narrativas para a produção de conhecimentos científicos, Ferrarotti (1988) esclarece:

Cada indivíduo não totaliza diretamente uma sociedade global, mas totaliza-a pela mediação do seu contexto social imediato, pelos grupos restritos de que faz parte, pois estes grupos são por sua vez agentes sociais ativos que totalizam o seu contexto, etc. De igual modo, a sociedade totaliza todo o indivíduo específico por intermédio de instituições mediadoras que 
a focalizam cada vez mais pontualmente para o indivíduo em questão. (FERRAROTTI, 1988, p. 31)

A validação aqui, se distancia dos modelos mecanicistas de hipótese e verificação. 0 que voga para a análise das narrativas, e para outros tipos de análise qualitativa, é o zelo por suas características essenciais de subjetividade e historicidade.

Ao trabalhar com narrativas, numa perspectiva biográfica, o pesquisador assume a sua presença e o seu devir por meio do encontro com os narradores e suas narrativas. Nesse sentido Santos (2002) afirma que nesse contexto, por ser de autoconhecimento, os conhecimentos científicos nascidos nas investigações são continuações dos sujeitos envolvidos.

Trabalhar com narrativas implica entender que a experiência e a narrativa são formas de acesso e, ao mesmo tempo, processo ativo de criação dos sentidos para as formas como mulheres e homens mobilizam conhecimentos, valores, desejos, na produção das suas subjetividades.

Abrahão (2006) afirma que um estudo que se realiza por meio de narrativas (auto)biográficas precisa assumir a sua tríplice constituição: a) Fenômeno - o ato de narrar-se; b) Método de investigação - produção e análise das fontes narrativas; e c) Processo de autoformação e de intervenção - reflexão sobre si e os modos singulares de produção da vida.

Em Territórios existenciais e narrativas de trajetórias escolares - uma aproximação, acolhe-se a expressão das subjetividades (percepções, conceitos, formas de enfrentamento, crenças, estratégias, modos de produção da vida, processos da cotidianidade, produção de desejos) dos narradores, reverenciando o duplo movimento de exposição do "eu" e partitha dos saberes por meio do qual homens e mulheres permitem apreender das suas experiências.
As entrevistas narrativas são infinitas em sua variedade, e nós as encontramos em todo lugar. Parece existir em todas as formas de vida humana uma necessidade de contar; contar histórias é uma forma elementar de comunicação humana e, independentemente do desempenho da linguagem estratificada, é uma capacidade universal. (JOVCHELOVITCH; BAUER, 2002, p. 91)

No que tange às entrevistas narrativas, Souza (2008) as compreende como o acesso (gravado ou escrito) às histórias pessoais ou narrativas dos sujeitos acerca de suas trajetórias de vida-formação. Souza (2006) enfatiza, ao tratar da realização de tais entrevistas, a importância da construção de um espaço de colaboração, autorrespeito e confiança, no qual

[...] quem decide o que deve ou não ser contado é o ator, a partir da narrativa da sua vida, não exercendo papel importante a cronologia dos acontecimentos e sim o percurso vivido pelo mesmo. Ainda que o pesquisador dirija a conversa, de forma sutil, é o informante que determina o 'dizivel' da sua história, subjetividade e os percursos da sua vida. (SOUZA, 2006, p. 29)

As fontes narrativas podem ser analisadas de distintas formas. Poirier (1999) propõe as análises interpretativa e compreensiva das histórias de vida. Bolívar (2002) lucubra sobre os desafios metodológicos para a análise de dados produzidos no âmbito das investigações narrativas. Pineau (2006) apresenta a triangulação formativa e as histórias de vida em contexto de pesquisa e de formação.

No entanto, Poirier (1999) reafirma a condição de corpus de pesquisa para as narrativas, ao descrevê-las como "[...] um material qualitativo constituído por um conjunto de histórias de vida, de sujeitos saídos de um universo populacional nitidamente definido e dos fins que se procura atingir [...]" (POIRIER, 1999, p. 108). Nesse sentido, porque produzidas em processo de pesquisa, as narrativas (auto)biográfi- 
cas priorizam as trajetórias, os percursos e as experiências dos sujeitos, estando marcadas pela historicidade e subjetividade nascidas das reflexões e análises construídas pelo narrador, no ato de lembrar, narrar e/ou escrever sobre si. "Os modelos biográficos assentam-se na inserção individual e coletiva da memória e nas histórias de vida, os quais centram-se na temporalidade, nos territórios, na individualização e individuação da existência e do sentido da vida". (SOUZA, 2008, p. 40)

\section{Tangenciando}

Eu entendi, ainda menina, que se eles (o governo) queriam que eu só estudasse um pouquinho, eu queria mais. Então eu sabia que tinha que fazer mais por mim e inventar os meus caminhos. (Mulungu) 6

Cartografar os Nômades do Saber é permitir-se experienciar o mergulho no palco imaterial das subjetividades humanas nascidas na escolarização, no preciso instante em que se busca acompanhar o "movimento que surge da tensão fecunda entre fluxo e representação" (ROLNIK, 2007, p. 67), no qual se (re)produzem percepções, afetos e intensidades de resistência e emancipação. São falas e gestos de silêncio, serenidade, excitação, reticência, interrogação, constatações rascunhadas - provisórias que são - pelo desejo e pela sapiência da vida vivida.

$\mathrm{Na}$ perspectiva deleuzo-guattariana, homens e mulheres constroem suas singularidades em processos de subjetivação e, em lugar de representar e significar fatos, eventos

6 Na investigação "Nômades do Saber: uma cartografia de trajetórias escolares migrantes na Bahia/Brasil", as narradoras estão denominadas por flores do sertão. A razão para a eleição está em Guimarães Rosa que, na obra "Grande Sertão: veredas" escreveu: "Sabe o senhor: sertão é onde o pensamento da gente se forma mais forte do que o poder do lugar" (ROSA, 2001, p. 41). As nômades são, assim, sete flores (Malva. Maracujá, Jitirana, Mussambê, Mulungu, Mucunã e Manacá), eleitas pela sua resistência às intempéries e distribuídas de forma aleatória entre as narradoras participantes da pesquisa. e fenômenos do mundo, Deleuze e Guattari propõem experimentar. A experimentação do mundo dá passo à produção das idiossincráticas subjetividades - singularização.

Na obra "Clínica e crítica" (1997), Deleuze diferencia migração de nomadismo, ao tratar tais movimentos como modos de subjetivação. Nessa perspectiva, a subjetividade migrante se estrutura em direção à suposta estabilidade dos territórios e suas estrias e se define entre origens e destinos. Por outro lado, o nômade volta-se para a incessante desterritorialização dos espaços lisos.

Por meio das Narrativas do Saber é possivel recuperar da trajetória nômade um movimento emancipador eclipsado pelo discurso centrado no fluxo e no rendimento escolar, posto que no ato da contação é possível acessar a:

[...] atividade reflexiva e interpretativa, de agir sobre si mesmos e sobre sua vida, de dar uma forma pessoal a inserções sociais, de escolher de alguma forma, senão seu destino, pelo menos sua existência. Essa relação reflexiva se traduz por uma aspiração à realização pessoal e por um olhar diferente dirigido sobre o desdobramento e sobre o sentido de uma existência aberta a múltiplos possiveis. (DELORY-MOMBERGER, 2012, p. 79)

As narrativas, os territórios, as linhas das subjetividades das Nômades são utilizadas como intercessores deleuzeanos. São eles que põem em devir os planos da imanência ${ }^{7}$ Nômade. A noção de intercessores, aqui, coaduna-se ao que foi proposto por Deleuze, na obra "Conversações" (1992).

0 essencial são os intercessores. A criação são os intercessores. Sem eles não há obra. Podem ser pessoas - para um filósofo, artistas ou cientistas; para um cientista, filósofos ou artistas mas também coisas, plantas, até animais, como

7 "A imanência não se reporta a um Algo como unidade superior a todas as coisas, nem a um Sujeito como ato que opera a síntese das coisas: é quando a imanência não é mais imanência a nenhuma outra coisa que não seja ela mesma que se pode falar de um plano de imanência". (DELEUZE, 2002, p. 12) 
em Castañeda. Fictícios ou reais, animados ou inanimados, é preciso fabricar seus próprios intercessores. (DELEUZE, 1992, p. 156)

Os intercessores são, portanto, mobilizadores do pensamento a partir dos quais os problemas são criados. Em Deleuze, os intercessores efetivam-se por meio dos componentes, das variações, da heterogeneidade, da multiplicidade e da intensidade. Os intercessores são sempre múltiplos, posto que somente o plural pode provocar o pensamento. Os intercessores deleuzeanos conotam a deriva, o devir e o desvio.

Os Nômades do Saber, enquanto problema, nascem por meio dos intercessores produzidos no encontro com as narradoras. Tais intercessores não estão colocados para representar ou apresentar suas vidas, crenças e ideias. Os intercessores ajudam a exprimir o que se passa nas/por entre as intersubjetivas experiências de afetação da pesquisadora, dos Nômades e dos Saberes, ao mesmo tempo que permitem ultrapassar a empiria do vivido, produzindo devires. E não poderia ser de outra maneira porque o Nômades do Saber é "[...] discurso de minoria, que se faz com intercessores" (DELEUZE, 1992, p. 157)

A escuta às narrativas esboça três territórios deleuzo-guattarianos.

A noção de território aqui é entendida num sentido muito amplo, que ultrapassa o uso que fazem dele a etologia e a etnologia. Os seres existentes se organizam segundo territórios que os delimitam e os articulam aos outros existentes e aos fluxos cósmicos. 0 território pode ser relativo tanto a um espaço vivido, quanto a um sistema percebido no seio do qual um sujeito se sente 'em casa'. o território é sinônimo de apropriação, de subjetivação fechada sobre si mesma. Ele é o conjunto de projetos e representações nos quais vai desembocar, pragmaticamente, toda uma série de comportamentos, de investimentos, nos tempos e nos espaços sociais, culturais, estéticos, cognitivos. (GUATTARI; ROLNIK, 2005, p. 323)
Para Deleuze e Guattari (1996), somos (indivíduos, grupos e territórios) atravessados por ao menos três qualidades de linhas que não cessam de, rizomaticamente, se misturar: linhas de segmentaridade dura, linhas de segmentaridade flexivel e linhas abstratas. São linhas do desejo bifurcando-se umas nas outras, uma e outra vez. Em verdade, "toda e qualquer formação do desejo no campo social se dá através do exercício ativo dessas três linhas - sempre emaranhadas, sempre imanentes uma às outras" (ROLNIK, 2007, p. 52).

Como as linhas, os territórios coexistem por meio de planos de continuidade que dissolvem a possibilidade de fronteiras rígidas e/ ou estáveis entre eles. Como as linhas, os territórios interpenetram-se, deslizam uns sobre os outros, se sobrepõem e interdigitam, constantemente. Isso porque subjetividades são espaço de eterna produção, atravessadas por in/confluências. A estabilidade, a previsibilidade e a imutabilidade não lhes são caras.

Como intercessores que são, colaboram para a expressão do vivido e sustentam o seu caráter de inacabamento. Ei-los:

a) Território trajetória escolar migrante: rotas e circuitos de escolarização, percurso migratório;

b) Território devir-estudante: tensões e enfrentamentos da vida vivida;

c) Território das oximoronias imanentes: o nomadismo do saber.

A seguir, um esboço dos territórios existenciais nascidos do estudo Nômades do Saber.

\section{Território trajetória escolar migrante: rotas e circuitos de escolarização, percurso migratório}

Não foi uma vida fácil. Era muito complicado abrir mão de tudo, de toda a infância em nome da escola, e eu fui abrindo mão. (Mucunã) 
O território Trajetória Escolar Migrante, compreendido como molar, permite afirmar que as trajetórias dos Nômades do Saber são expressão dos agenciamentos do desejo atravessado pelas linhas de força do sistema escolar.

Para ter acesso ao percurso escolar e aos deslocamentos físicos, os narradores preencheram um "Instrumento para a produção de dados sobre trajetória escolar migrante (percurso escolar, deslocamento por motivo de estudos e migração estudantil)", construído para a investigação que deu origem a este artigo. 0 instrumento dá acesso a informações referentes: a) às etapas institucionalizadas do percurso escolar (níveis e modalidades de ensino, turno de estudos, dependência administrativa da instituição escolar, organização curricular); b) ao fluxo escolar (promoção, retenção, evasão e transferência); c) à movimentação espacial por Territórios de Identidade ${ }^{8}$ e municípios (em consonância com a orientação do Estado da Bahia para a produção e a divulgação de dados sociais, ambientais e econômicos, constante no Plano Plurianual 2008/2011) Estado e países.

Por meio dessas informações, contextualizadas com as estatísticas da educação e as políticas públicas, é possível refletir sobre as linhas de força do saber-poder que se apresentam no "Território trajetória escolar migrante", na forma de rotas e circuitos de escolarização e percurso migratório.

Os circuitos de escolarização são um

8 De acordo com a SEPLAN (Secretaria do Planejamento do Estado da Bahia), Territórios de Identidade são definidos como: "um espaço físico, geograficamente definido, geralmente contínuo, caracterizado por critérios multidimensionais, tais como o ambiente, a economia, a sociedade, a cultura, a política e as instituições, e uma população com grupos sociais relativamente distintos, que se relacionam interna e externamente por meio de processos específicos, onde se pode distinguir um ou mais elementos que indicam identidade, coesão social, cultural e territorial". Disponivel em: <http://www.seplan.ba.gov.br/modules/ conteudo/conteudo.php?conteudo=17>. Acesso em: 24 abr. 2016. constructo teórico apresentado por Souza (1990/1991), que aponta para a construção de dois circuitos formativos, denominados como virtuoso e vicioso.

No seu conjunto o sistema educacional apresenta uma estrutura de funcionamento dicotômica em que operam dois circuitos: um circuito 'virtuoso' que passa pelas escolas particulares de 10 e 2 o graus e pelo sistema público de 3 응 grau; e um circuito 'vicioso' que opera nas escolas públicas de 10 e 20 graus e na rede de faculdades e universidades particulares de baixa qualidade. (SOUZA, 1990/1991, p. 27)

Como a definição inicial de Souza (1990/1991) não prevê casos onde ocorra a alternância de instituições públicas e particulares, nas etapas correspondentes ao ensino fundamental, médio, ou superior, a denominação "circuito vicioso" abrangerá tais itinerários. Souza (1990/1991) também não atribuiu nome aos percursos nos quais a escolarização ocorra, inteiramente, em instituições públicas. No âmbito deste estudo, denomina-se como "circuito democrático" ao percurso escolar que expressa uma trajetória assegurada pela oferta pública de ensino, em todos os níveis da escolaridade.

Os circuitos, porque pensados com base em instituições e níveis de ensino, apontam para as estrias normativas do sistema escolar e, consequentemente, para os alisamentos das trajetórias estudadas.

Os movimentos físicos, presentes nas narrativas, estão descritos em nivel de Território de Identidade, município, Estado e país, e categorizados como intraterritorrial e interterritorial. A primeira categoria refere-se às circulações dentro de um município ou Território de Identidade ou Estado ou país. A segunda nomeia os movimentos entre municípios, Territórios de Identidade, Estados e países.

As rotas de escolarização referem-se à movimentação espacial (física e simbólica), em 
nível de modalidade de ensino; turno de estudo; organização curricular; dependência administrativa da instituição; inter e intramunicípio, Território de Identidade, Estado, região, país. As rotas auxiliam a percepção da Trajetória Escolar Nômade e os seus deslocamentos.

As rotas auxiliam a percepção do fenômeno da migração estudantil, nos casos estudados, corroborando o processo de aproximação das histórias e trajetórias. A análise dos itinerários formativos - rotas - a partir dos níveis de ensino e das instituições frequentadas, por dependência administrativa, permite o estudo dos circuitos. O olhar voltado para os caminhos pelo território baiano indica os movimentos migratórios.

\section{Território devir-estudante: tensões e enfrentamentos da vida vivida}

Eu sempre fui movida pela escola e em nome da escola eu fui... (Mucunã)

Os territórios Devir-estudante e Oximoronias imanentes foram tecidos por meio da escuta às entrevistas narrativas e ao grupo focal realizado com os Nômades participantes da pesquisa. Por meio das suas molecularidades e linhas de fuga, as subjetividades e os processos de subjetivação tomam forma e se fazem visiveis.

Se em nivel molar, os Nômades do Saber sujeitam-se, solicitam e assumem o reconhecimento dos títulos e certificados formais, em nível molecular, são um devir-minoritário na escolarização. Um devir estudante é, acima de tudo, uma experimentação de intensidades do aprender. Os Nômades, enquanto minoria, “[...] representam não só pólos de resistência, mas potencialidades de processos de transformação" (DELEUZE; GUATTARI, 1997, p. 88). A experimentação do devir é produção de territórios singulares de criação onde é possível ultrapas- sar os dualismos da molaridade. E os Nômades o fazem.

Desde pequena eu tinha um desejo muito grande de estudar, mas eu não tinha idade. Não sei se era falta de informação ou se era assim nessa época, mas a escola só matriculava a partir dos 7 anos. Eu tinha dois irmãos mais velhos que já iam pra escola e eu chorava todos os dias porque eu queria ir pra escola também. A escola era muito distante e tinha que ir a pé. Mesmo sem matrícula e permissão eu ia com os meus irmãos. Eu era bem miudinha e a mais de teimosa. Então, entre os 4 ou 5 anos, era assim que eu ia pra essa escola. Foi quando eu comecei a ser clandestina na escola. (Jitirana)

O nomadismo, aqui, revela-se nos jeitos e intensidades que o atravessam diuturnamente. Suas formas de pensar, sentir e estar na vida; suas maneiras de lidar com as regras, as leis e as abordagens de vigilância e punição; suas alternativas para habitar, conviver e deslocar-se; seus modos de afetar e serem afetadas revelam uma "[...] microtessitura da vida subjetiva, nas diferentes maneiras que entendemos nossas existências" (GUATTARI; ROLNIK, 2005, p. 53).

Os Nômades do Saber desejam ardentemente e desejar é constituir-se em devires construindo a própria realidade. 0 devir-estudante, enquanto linha de fuga, mobiliza paixões e ações, atos e enunciados que desterritorializam os jogos essencialistas da escolarização.

O devir-estudante concretiza um desejo de estudar, aprender e saber, que vai além das políticas de formação acadêmica e profissional. O devir-estudante encarna o desejo pelo Saber e pelo Saber-se, o fluir de subjetividades ainda não capturadas, ainda não cooptadas pela máquina capitalística.

É importante atentar para o fato de que não existem dualismos entre o molar e o molecular, pois “[...] toda sociedade, mas também todo indivíduo, são pois atravessados pelas 
duas segmentaridades ao mesmo tempo: uma molar e outra molecular" (DELEUZE; GUATTARI, 1996, p. 82).

A imanência é o espaço aberto onde os Nômades do Saber refletem sobre a escolarização problematizando-a em dobras. 0 ato de dobrar o pensamento para pensar a imanência produz singularidades. Os modos de subjetivação são dobras da imanência. Os processos de singularização nascidos da imanência da escolarização originam os modos de subjetivação. Da concretização/experimentação da escolarização e suas trajetórias emerge o modo de subjetivação Nômade.

\section{Território das oximoronias imanentes: o nomadismo do saber}

Eu morava de um lado e estudava do outro. Era o rio o que separava os municípios. Ele dividia e também unia. 0 rio era uma entidade, tinha um poder e tinha um saber. 0 rio era dele mesmo. (Manacá)

A noção de nomadismo está presente, na obra de Deleuze, nos livros "Diferença e repetição" (1998) e no volume V de "Mil Platôs" (1997). Neles, a abordagem do nomadismo ocorre em duas perspectivas: uma abordagem ontológica e uma abordagem político revolucionária. A primeira aponta para o devir da existência e a segunda para a resistência.

A escolarização é, eminentemente, um espaço para a construção de aprendências. Por aprendências, no contexto das subjetividades, se entendem processos de conceder-se a autoria de pensamentos oriundos da assunção das diferenças e de reconhecimento das alteridades. Todavia, se é no campo do simbólico que ocorrem as aprendências, é no mesmo território que o Estado, na qualidade de herdeiro do governo dos desejos, desautoriza singularidades, controlando e instituindo o espaço, o tempo, as formas de aprender, os saberes permitidos e os sujeitos que podem possuir este ou aquele saber.

A saída, para os que precisam emanciparse, é desterritorializar-se e escapar. A fuga não é da escolarização, mas do controle do desejo. E o desejo é, acima de tudo, de diferir.

É uma escolha o que venho fazendo a cada dia. Não foi uma questão do que foi acontecendo, da vida que foi me levando para esse destino. Não. Eu quis, fui eu que escolhi. Porque se fosse pela questão de seguir a lógica da vida, se fosse pelo que a mim era oferecido, eu não estaria aqui hoje. Tenho certeza. Então, foi tudo escoIha minha. (Mulungu)

O Nômade do Saber escapa da escolarização escolarizando-se. A trajetória escolar por meio da qual o nômade se escolariza produz trajetórias, aprendizagens e saberes Menores. É um fato que, apesar das capturas, as aprendizagens e os saberes menores insistem, persistem, brotam, proliferam e fugazes, desaparecem... mas resistentes, reaparecem, em outro lugar.

\section{FUGA. .}

As narrativas das trajetórias escolares fazem surgir o espaço biográfico na compreensão dos processos de escolarização no contexto da reconfiguração das subjetividades contemporâneas. Este espaço de deslocamento e reconstruções faz com que as narrativas, como caminhos para si (JOSSO, 2004), se convertam em dobras - espaços para pensar o pensamento - das dobras da escolarização.

Quem eu sou hoje é porque eu tive tantos outros encontros e conheci outras pessoas e convivi com pessoas diferentes. 0 que nos leva ao que a gente é vai se construindo a cada dia. (Malva)

As narrativas de trajetórias escolares podem ser analisada por meio de cartografias e trazer à tona territórios existenciais que ex- 
pressem maneiras de agenciar o desejo de saber na realidade brasileira. No caso da pesquisa Nômades do Saber, os territórios Trajetória Escolar Migrante, Devir Estudante e Oximoronias Imanentes revelam os agenciamentos produzidos por estudantes baianos.

As narrativas das trajetórias escolares dos Nômades do Saber revelam que suas subjetividades existem e se formam no processo de escolarização porque o nomadismo, que thes é intrínseco, os autoriza a criar, recriar e reconhecer-se realizando o próprio desejo e, certamente, o concretizará, posto que:

No coração de uma árvore, no oco de uma raiz ou na axila de um ramo, um novo rizoma pode se formar. Ou então é um elemento microscópico da raiz da árvore, uma radícula, que incita a produção de um rizoma. (DELEUZE; GUATTARI, 1995, p. 24)

Sobre o uso dos territórios existenciais como estratégia para a análise e a interpretação de narrativas, o artigo Territórios exis-

\section{Referências}

ABRAHÃO, Maria Helena Menna Barreto. As narrativas de si ressignificadas pelo emprego do método autobiográfico. In: SOUZA, Eliseu Clementino de; ABRAHÃO, Maria Helena Menna Barreto. (Orgs.). Tempos, narrativas e ficções: a invenção de si. Porto Alegre: EDIPUCRS; Salvador: EDUNEB, 2006. p. 149-170.

BARROS, Laura Pozzana; KASTRUP, Virgínia. Cartografar é acompanhar processos. In: PASSOS Eduardo; KASTRUP Virgínia; ESCÓSSIA Liliana. Pistas do método da cartografia: pesquisa-intervenção e produção de subjetividade. Porto Alegre: Editora Sulina, 2010. p. 52-75.

BERTAUX, Daniel. Narrativas de vida: a pesquisa e seus métodos. Natal: Editora EDUFRN; São Paulo: Editora Paulus, 2010.

BOLÍVAR, Antonio. ¿De nobis ipsis silemus?: epistemologia de la investigación biográfico-narrativa em educación. Revista Electrónica de Investigación tenciais e narrativas de trajetórias escolares - uma aproximação ousa afirmar que para os que desejam: a) abordagens que permitam o estudo do que está em curso (fatos, fenômenos, processos) e que tal seja anunciado/lucubrado pela voz de quem o produz; b) trazer à tona inter-relações entre homens e mulheres narradores, suas singularidades e suas vidas vividas; c) acompanhar processos ativos de criação dos sentidos para as formas como mulheres e homens mobilizam conhecimentos, valores e desejos, para a produção das suas subjetividades; e d) visibilizar os movimentos e resistências micropolíticas onde os sujeitos se constituem, revelando os jogos de poder e enfrentamentos, os modos de objetivação e de subjetivação e as formações rizomáticas da cartografia deleuzoguattariana, os seus territórios existenciais são uma excelente estratégia para análise/ interpretação de narrativas de trajetórias escolares ou não.

Educativa, México, Universidad Autónoma de Baja California, v. 4, n. 1, p. 1-26, fev. 2002.

BOURDIEU, Pierre. Préface. In: DOISE, Willem; CLEMENCE, Alain; LORENZI-CIOLDI, Fabio. Représentations sociales et analyses de données. Grenoble: P.U.G., 1992. p. 2-3.

BOURDIEU, Pierre. Os três estados do capital cultural. In: NOGUEIRA, Maria Alice; CATANI, Afrânio. (Orgs.). Escritos de Educação. 2. ed. Petrópolis, RJ: Vozes, 1999. p. 73-79.

CAIAFA, Janice. Aventura das cidades. Rio de Janeiro: Ed. FGV, 2007.

CLANDININ, Jean; CONNELlY, Michael. Pesquisa narrativa: experiências e história na pesquisa qualitativa. Tradução: Grupo de Pesquisa Narrativa e Educação de Professores ILEEL/UFU. Uberlândia, MG: EDUFU, 2011. 
DELEUZE, Gilles; GUATTARI, Félix. Kafka: por uma literatura menor. Trad. Julio Castañon Guimarães. Rio de Janeiro: Imago, 2014.

DELEUZE, Gilles. Conversações. Trad. Peter Pál Pelbart. Rio de Janeiro: Ed. 34, 1992.

DELEUZE, Gilles. Diferença e repetição. Trad. Luiz Orlandi e Roberto Machado. Rio de Janeiro: Graal, 1988.

DELEUZE, Gilles. Crítica e clínica. Trad. Peter Pál Pelbart. São Paulo: Ed. 34, 1997.

DELEUZE, Gilles. A imanência: uma vida... Educação \& Realidade, Porto Alegre, v. 27, n. 2, p. 10-18, jul./ dez. 2002.

DELEUZE, Gilles; GUATTARI, Félix. Mil platôs: capitalismo e esquizofrenia. v. 1. Trad. Ana Lúcia de Oliveira, Aurélio Guerra Neto e Célia Pinto Costa. Rio de Janeiro: Ed. 34, 1995.

DELEUZE, Gilles, GUATTARI, Félix. Mil platôs: capitalismo e esquizofrenia. v. 3. Trad. Aurélio Guerra Neto, Ana Lúcia de Oliveira, Lúcia Cláudia Leão e Suely Rolnik. Rio de Janeiro: Editora 34, 1996.

DELEUZE, Gilles; GUATTARI, Félix. Mil Platôs: capitalismo e esquizofrenia. v. 5. Trad. Peter Pál Pelbart e Janice Caiafa. Rio de Janeiro: Editora 34, 1997.

DELEUZE, Gilles; PARNET, Claire. Diálogos. Trad. Eloísa Araújo Ribeiro. São Paulo: Escrita, 1998.

DELORY-MOMBERGER, Christine. Abordagem metodológica na pesquisa biográfica. Revista Brasileira de Educação, v. 17, n. 51, p. 523-740, set./dez. 2012.

ELBAZ-LUWISCH, Freema. O ensino e a identidade narrativa. Revista de Educação, Lisboa, v. 11, n. 2, p. 21-33, 2002.

FERRAROTTI, Franco. Sobre a autonomia do método biográfico. In: NÓVOA, António; FINGER, Matthias. (Orgs.). 0 método (auto)biográfico e a formação. Lisboa: Ministério da Saúde/ Departamento de Recursos Humanos, 1988. p. 17-34.

GUATTARI, Félix; ROLNIK, Suely. Micropolítica: cartografias do desejo. Petrópolis, RJ: Vozes, 2005.

JOSSO, Marie-Christine. As histórias de vida abrem novas potencialidades às pessoas: entrevista com Marie-Christine Josso. Aprender ao longo da vida, $n$. 2, p. 16-23, 2004.

JOVCHELOVITCH, Sandra; BAUER, Martin. Entrevista narrativa. In: GASKEL, George; BAUER, Martin. (Orgs.). Pesquisa qualitativa com texto, imagem e som: um manual prático. Petrópolis, RJ: Vozes, 2002. p. 90-113.

LABOV, William. The transformation of experience in narrative sintax. In: (Ed.). Language in the Inner City. Philadelphia: University of Pennsylvania, 1972. p. 352-96. Speech actions and reactions in personal narrative. In: TANNEN, Deborah. (Ed.). Analyzing discourse: text and talk. Washington: Georgetown University Press, 1982. p. 12-44.

LINS, Daniel. Mangue's school ou por uma pedagogia rizomática. Educação \& Sociedade, Campinas, v. 26, n. 93, p. 1229-1256, set./dez. 2005.

MAFFESOLI, Michael. Sobre o nomadismo. Vagabundagens pós-modernas. Trad. Manoel de Castro. Rio de Janeiro: Record, 2001.

MIZUKAMI, Maria da Graça Nicoletti. Docência, trajetórias pessoais e desenvolvimento profissional. In: REALI, Aline Maria de Medeiros Rodrigues; MIZUKAMI, Maria da Graça Nicoletti. (Orgs.). Formação de professores: tendências atuais. São Carlos, SP: EDUFSCar, 1996.

NOGUEIRA, Maria Alice. A construção da excelência escolar - um estudo de trajetórias feito com estudantes universitários provenientes das camadas médias intelectualizadas. In: NOGUEIRA, Maria Alice; ZAGO, Nadir; ROMANELLI, Geraldo. (Orgs.). Família e escola: trajetórias de escolarização em camadas médias e populares. Petrópolis, RJ: Vozes, 2000. p. 125-154.

NOGUEIRA, Cláudio; FORTES, Maria de Fátima. A importância dos estudos sobre trajetórias escolares na Sociologia da Educação contemporânea. Revista Paidéia, Belo Horizonte, Ano III, n. 2, 2004 Disponível em: <http://www.fumec.br/revistas/index.php/ paideia/article/view/1339>. Acesso em: abr. 2016.

NÓVOA, António. Os professores e as histórias de sua vida. In: (Org.). A vida de professores.

Porto: Porto Editora, 2000. p. 11-30. 
PINEAU, Gaston. Temporalités em formation: vers de nouveaux synchroniseurs. Paris: Anthropos, 2000.

PINEAU. Gaston. As histórias de vida em formação: gênese de uma corrente de pesquisa-ação-formação existencial. Educação e Pesquisa, v. 32, n. 2, p. 329-343, mai./ago. 2006.

POIRIER, Jean et. alii. Histórias de vida: teoria e prática. Trad. de João Quintela. Oeiras: Celta, 1999.

RIESSMAN, Catherine. Narrative analysis. California: Sage, 1993.

ROLNIK, Sueli. Cartografia sentimental. Porto Alegre: Sulina, 2007.

ROSA, Guimarães. Grande sertão: veredas. Rio de Janeiro: Nova Fronteira, 2001.

SANTOS, Boaventura de Souza. Um discurso sobre as ciências. Portugal: Afrontamento, 2002.

SANTOS, Milton. Por uma outra globalização: do pensamento único à consciência universal. 6 . ed. Rio de Janeiro: Record, 2001.

SOUZA, Eliseu Clementino de. Modos de narração e discursos da memória: biografização, experiências e formação. In: PASSEGGI, Maria da Conceição; SOUZA, Eliseu Clementino de. (Orgs.). (Auto)biografia: formação, territórios e saberes. São Paulo: Paulus, 2008. p. 85-101.

SOUZA, Eliseu Clementino de. A arte de contar e trocar experiências: reflexões teórico-metodológicas sobre história de vida em formação. Revista Educação em Questão, Natal, v. 25, n. 11, p. 22- 39, jan./ abr. 2006.

SOUZA, Paulo Renato. A universidade e a crise da educação. Revista da USP, n. 8, p. 27-32, dez./fev. 1990/1991.

ZAGO, Nadir. Do acesso à permanência no ensino superior: percursos de estudantes universitários de camadas populares. Revista Brasileira de Educação, v. 11, n. 32, p. 226-237, mai./ago. 2006.

ZOURABICHVILI, François. 0 vocabulário de Deleuze. Trad. André Telles. Rio de Janeiro: Relume Dumará, 2004.

Recebido em: 15/05/2016

Aprovado em: 30.07.2016

Dina Maria Rosário dos Santos é doutoranda em Ciências Sociais e Jurídicas pela Universidad de Cádiz/Es, Mestre em Orientação e Avaliação SocioEducativas pela Universidad de Cádiz/Es, Psicopedagoga, Pedagoga. Docente da Universidade do Estado da Bahia; fundadora e coordenadora do Núcleo Integrado de Psicologia e Psicopedagogia - NIPP/DEDC XIII; Coordenadora do Grupo de Estudos Rizomar-Diálogos Deleuzo-Guattarianos e Eliaseanos para Pensar a Educação; Coordenadora da pesquisa departamental "Nômades do saber: um estudo sobre migração estudantil". Membro do Grupo de Pesquisa Educação Ciência e Tecnologia/IFBA-Vça. E-mail: dmrsantos@uneb.br

UNEB-DEDC XIII: Avenida Luiz Viana Filho, S/N, Bairro Batalhão, Itaberaba, Bahia, CEP 46880-000 